\title{
INTEGRATED NATURAL RESOURCE AND CONSERVATION DEVELOPMENT PROJECT: A REVIEW OF SUCCESS FACTORS FROM A SYSTEMS PERSPECTIVE
}

\author{
Rajski, Pauline Victoria (1); \\ Papalambros, Panos Y (2) \\ 1: Industrial and Operations Engineering, University of Michigan; \\ 2: Mechanical Engineering, University of Michigan
}

\begin{abstract}
Integrated Natural Resource and Conservation Development (INRCD) Projects is an umbrella term for a variety of Integrated Conservation and Development Projects (ICDPs), a concept first introduced by the World Wide Fund for Nature in the mid 1980s to target practice-oriented efforts in developing countries; and Integrated Natural Resource Management (INRM) research and development projects introduced as adaptive management for fisheries, wildlife, forest, and rangeland to target analysisoriented efforts in developing and developed countries. Both efforts seek to balance economic development and natural resource conservation. This paper reviews the literature over the past four decades in an attempt to determine which planning and execution methods lead to greater success. A thematic analysis revealed three broad areas of importance: community inclusion and income diversification, inadequate training and management, and inability to properly quantify data. A systems design optimization approach for such projects is advocated to support project decision making in these areas of importance.
\end{abstract}

Keywords: Participatory design, Integrated Natural Resource and Conservation Development, Integrated Conservation and Development Projects, Sustainability, Optimisation

\section{Contact:}

Rajski, Pauline Victoria

AFRICA-DESIGN

University of Michigan - Optimal Design Laboratory

United States of America

prajski@umich.edu

Cite this article: Rajski, P. V., Papalambros, P. Y. (2021) 'Integrated Natural Resource and Conservation Development Project: A Review of Success Factors from a Systems Perspective', in Proceedings of the International Conference on Engineering Design (ICED21), Gothenburg, Sweden, 16-20 August 2021. DOI:10.1017/pds.2021.448 


\section{INTRODUCTION}

Conservation of natural resources and the economic development that depends on the use of these resources are often seen as competing objectives. The United Nations Sustainable Development Goals (SDGs) include conservation of land, water, and other resources as a top priority for sustainable development (Nhamo 2019). These competing objectives of sustainable development present difficult tradeoff decisions in the planning and execution of such projects. We posit that a systems design optimization framework offer a natural opportunity to explore the role of design in sustainable development projects in a quantitative manner. As a first step towards such a framework, the present review paper aims to determine the planning and execution factors for success or failure of such projects over the past four decades.

To accommodate both conservation and development, the World Wide Fund for Nature (WWF) first introduced the concept of Integrated Conservation and Development Projects (ICDPs) in the mid 1980s; these are practice oriented and target developing countries (Barrett et al. 1995). The concept of Integrated Natural Resource Management (INRM) was also introduced as adaptive management for fisheries, wildlife, forest, and rangeland management, often associated with ecotourism (Ochola et al. 2013); these are analysis oriented and target more developed countries. Both approaches seek to balance economic development and land and natural resource conservation, and so in the remainder we use the broader term Integrated Natural Resource and Conservation Development Projects (INRCDs) that combines both approaches and elements of participatory action research.

System design optimization offers a quantitative process for studying such trade-offs (Papalambros et al. 2017). To pave the way for INRCD system optimization studies, this paper reviews the related extant literature and offers some observations on successes to date and the challenges ahead. This review is a continuation of previous reviews on the status of design for sustainable development within the Design Society's AFRICA-DESIGN initiative (Barlow et al. 2020; Mitropoulos et al. 2020; Design Society 2021). A thematic analysis of the literature reveals three broad areas of importance: community inclusion and income diversification, inadequate training and management, and inability to properly quantify data. The implications are that, besides technical functional modeling, the systems optimization framework must account for social impact, and for incomplete and stochastic data.

\section{LITERATURE REVIEW}

\subsection{Methodology}

A systematic literature review and a secondary analysis of past case studies were undertaken. There is a wide range of approaches and terminology used in INRCD projects. We examined the literature from the early 1990s to late 2010s to identify challenges that have endured and those that have been resolved. Many issues have resurfaced over time and they are addressed here along with opportunities for addressing them through the system optimization lens. The goal of the review is to provide context for the development of an appropriate systems design optimization model for INRCDs and to justify the need for a quantitative process that can measure success across INRCD projects, thus contributing to ongoing studies on design for sustainable development.

\subsubsection{Dataset construction and inclusion criteria}

The review focused on papers dealing with conserving the environment while contributing to economic development, particularly those addressing system optimization in INRM and ICDP as noted above, but also work under the terms Community-Based Natural Resource Management (CBNRM), grassroots conservation, people-centred conservation, Adaptive Management (AM), Adaptive Resource Management (ARM), and Adaptive Environmental Assessment and Management (AEAM). We use the term INRCD as an umbrella term for all these terms. The definitions for all the key terms explored in this review are shown in Table 1. A starting point for the review was the book Managing Natural Resources for Development in Africa (Ochola et al. 2013) augmented by traditional keyword search. 


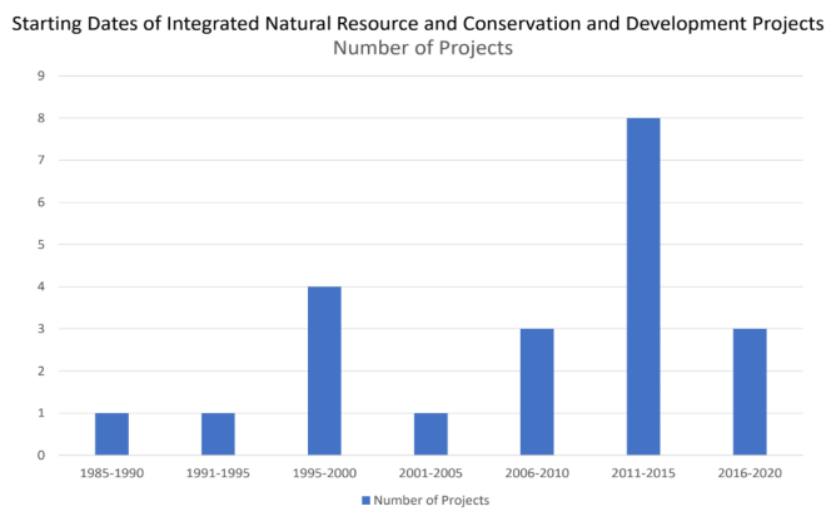

Figure 1. Organization of INRCD projects based on starting period

The primary inclusion criterion was that the work examined trade-offs between conservation and development, rather than focusing only on conservation or development. A keyword search in abstracts of peer-reviewed journal articles and in books was conducted as described in the next section focusing on Africa and few instances in East Asia. Literature on agricultural systems and biodiversity was included. We excluded papers addressing only conservation or only development, and optimization papers not directed specifically to INRCD. The final dataset included 52 journal articles with 123 authors, 6 dissertations, and 7 books with 13 authors. A summary of projects by starting period is shown in Figure 1. The complete database can be found in the INRCD Database (2021).

\subsubsection{Keyword and thematic analyses}

The search path and decomposition are shown in Fig. 2 effected through identification of common terms (Kevork 2009) and going more deeply in search of quantification methods utilized in the work. Optimization models were looked into as a concept for solving some of the challenges presented. Following Ruszczynski and Shapiro (2009) optimization was identified as a promising approach, and various types of optimization models were encountered.

To identify patterns of successes and challenges, a thematic analysis was conducted rather than a content analysis, giving us a more detailed account of the results (Braun et al. 2014). Since similar project failures have been identified over several decades, a thematic analysis could provide a better understanding for failure causality. Strengths and weaknesses were identified relating to project planning, implementation, results, and impact on the local community. The optimization papers were analysed through a similar approach but focusing more on (i) how realistically the model calculated uncertainty and (ii) the extent to which the model coincided with the indigenous community knowledge.

\subsection{Thematic analysis results}

The most common challenges identified were absence of community ownership, income diversity, improper training and transition periods, and lack of benefits from quantitative analysis. We discuss these briefly below. In a contrapositive sense, the more successful projects were those that managed these challenges better.

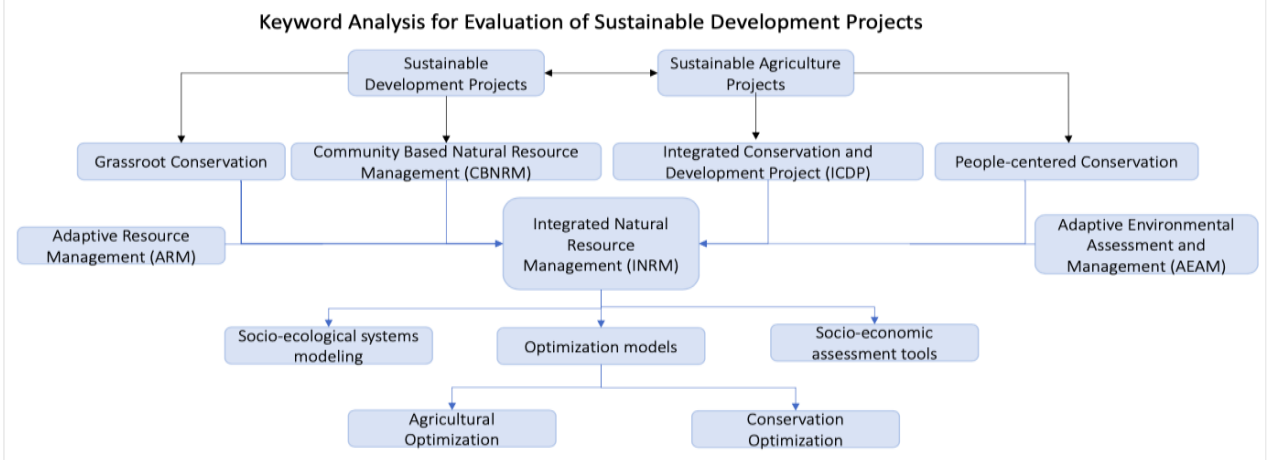

Figure 2. Keyword Analysis for Evaluation of INRCD Projects 


\subsubsection{Community inclusion and income diversity}

Direct inclusion of communities from the start of the planning and implementation process is crucial. Despite the ability to do extensive research, the most valuable information during an integrated project is indigenous knowledge. The ability to work with community members can provide (i) insightful

Table 1. Definitions of common key terms related to INRCD projects

\begin{tabular}{|c|c|}
\hline Key Term & Definition \\
\hline $\begin{array}{l}\text { Adaptive Resource Management } \\
\text { (ARM) }\end{array}$ & $\begin{array}{l}\text { Structured, iterative process for decision making (Larson } \\
\text { 2012). }\end{array}$ \\
\hline $\begin{array}{l}\text { Community and Wildlife } \\
\text { Management (CWM) }\end{array}$ & $\begin{array}{l}\text { Rural communities hold management responsibility and } \\
\text { ownership rights for resources (Songorwa 1999). }\end{array}$ \\
\hline $\begin{array}{l}\text { Community Based Natural } \\
\text { Resource Management (CBNRM) }\end{array}$ & $\begin{array}{l}\text { Integrated approach to integrated conservation through the } \\
\text { use of shared land (Ochola et al. 2013). }\end{array}$ \\
\hline $\begin{array}{l}\text { Integrated Conservation and } \\
\text { Development Projects (ICDP) }\end{array}$ & $\begin{array}{l}\text { Development projects that aim to conserve biodiversity and } \\
\text { ecological systems in developing nations (Alpert 1996) }\end{array}$ \\
\hline $\begin{array}{l}\text { Integrated Natural Resource and } \\
\text { Conservation Development } \\
\text { (INRCD) }\end{array}$ & $\begin{array}{r}\text { Holistic approach to conserving natural resources while } \\
\text { focusing on the alleviation of poverty and economic } \\
\text { development }\end{array}$ \\
\hline $\begin{array}{l}\text { Integrated Natural Resource } \\
\text { Management (INRM) }\end{array}$ & $\begin{array}{l}\text { Holistic approach to managing resources and development } \\
\text { projects in a systematic method which various aspects such as } \\
\text { bio-physical, social, and economic (Ochola et al. 2013). }\end{array}$ \\
\hline
\end{tabular}

information on sustainable alternative sources of income, (ii) accurate current state of the area being conserved, and (iii) opportunities for improvement (Ochola et al. 2013). For the community to be supportive, they must see a clear benefit from the project. While the goal is long-term economic development, a short-term benefit is needed to maintain engagement (Gadgil et al. 1993). Short-term benefits usually are monetary ones, greater or equal to what the community members had prior to the implementation of the project. These social benefits can be modelled using social science research and placed as objectives in a system optimization framework to determine the optimal scenarios for quantifying benefits trade-offs. This quantitative process can improve standards of living by identifying which factors in an environment contribute to different social benefits.

For example, the CAMPFIRE project began in 1989 in Zimbabwe faced a variety of challenges derived from lack of community engagement (Balint et al. 2006). With only about half of the revenue directly going to the community and the rest to government officials and external stakeholders, the project was not successful in alleviating poverty with each of the 100,000 households making on average \$5 USD/ by 2001 (Balint et al. 2006). In another example, in Kenya's Ngong Road Forest project so little was provided for people that they would sneak out at night to collect more wood for fuel (Kosgey 2015). Prioritizing the community needs in these projects is necessary for a sustainable use of resources (Gadgil et al. 1993) and a methodology to model these needs can be used to predict the outcome of INRCD projects and reduce the probability of failure.

There are several options for community sources of income, for example, ecotourism was suggested in the Ngong Road Forest project (Kosgey 2015) -- an idea applicable to other projects in biologically diverse and attractive locations. However, external income is not sufficient. For example, the District Environmental Action Planning project in Zimbabwe relied too heavily on donor contributions which led to instability (Manjengwa 2007). Again, the foundation for an INRM must be rooted in the benefits of the local community. In the long-term, any external stakeholders will likely not be involved in the project anymore; however, the community members will always be there (Catacutan et al. 2007).

Diversification of livelihoods and income sources is important for community (Makate et al. 2016). Moreover, there is a strong correlation between conservation and alleviation of poverty (Kepe et al. 
2004). Land use in often the only source of income for individuals. Projects emphasizing sustainable management of wildlife resources, including scientific, recreational, nutritional, and artistic values, have higher probability for success. The greater the number and amounts of benefits from conservation, the more engaged the community members will remain (Ajayi 2019).

There is also a strong correlation between diversification of livelihoods and alleviation of poverty (Kepe et al. 2004). Local community participation increases as more stakeholders are engaged with the various options for income sourcing (Catacutan et al. 2007). Individuals have different strengths and skills, providing them with opportunities to utilize those skills increases the chances of success. Indigenous knowledge can point to alternate, more sustainable, income sources derived from conservation (Gadgil et al. 1993) The wider the options for sustainable income sources and poverty reduction, the greater the economic development benefit.

A Marine Integrated Conservation and Development project in Indonesia had a multitude of income sources increasing the project's potential for success. An increase in wealth and income after the implementation of the project was attributed to "a number of project activities aimed at improving livelihoods and living conditions in general, such as farm productivity training, revolving funds for fishing gear, and construction to prevent floods" (Gurney et al. 2014). The Arabuko Sokoke Forest and Kakamega Forest project in Kenya faced challenges due to lack of diversified livelihoods (Ouko 2018), where individuals not directly involved in the limited conservation activities refused to participate (Gadgil et al. 1993). The Amani Butterfly Project in Tanzania would have been more successful with a more diversified livelihood (Morgan-Brown et al. 2010) if other sources of income became available besides butterfly farming, and conservation behaviours would have spread beyond the specific farmers. Yet, there are often greater factors preventing diversification. A major factor is the inability to create a sustained credit market (Barrett et al. 2001). For example, farmers could not buy trucks to transport their product to local markets, because loans were unavailable (Barrett et al. 2001) despite the potential for lucrative long-term income.

An INRCD project is a collection of subsystems that must work together to reach sustainable development. It can be difficult to predict the success of an INRCD ahead of time due to the lack of quantitative tools; the development of a systems optimization model will allow prediction of the outcomes of an INRCD ahead of time under different assumptions and scenarios, thus allowing for improved decision making and planning before project implementation.

\subsubsection{Management and training}

The best approach for community inclusion is to include community members in leadership and management positions. However, such members must be provided with proper training and tools so they can be successful. To increase the chances of project success the transition from an unsustainable to a sustainable source of income must be prioritized, and community members must be trained from the early project stages (Gadgil et al. 1993). Development and training in systems optimization thinking, let alone modelling, can support the process of decision-making helping managers make better qualitative, and even quantitative, decisions that contribute to the success of a project.

An ICDP project at the Korup National Park in Cameroon during 2015-16 aimed at a road construction to provide the farming and produce community with easier access to markets -- with agriculture becoming an alternate source of income to poaching (Spey et al. 2019). Despite individuals in previously higher-income households noticing an increase in household income, anyone in below- median-income households did not experience any increase (Spey et al. 2019). While the latter households had road access, they did not have the skills needed for starting and maintaining a business along the road or for agriculture (Spey et al. 2019.). Despite the efforts made, most of the community members were unable to benefit from the opportunities provided by access to a marketplace, relating back to the need for proper implementation methods and a strong focus on social benefits.

Similar problems arose in projects in Kenya, where the main reason for non-participation within the project was lack of knowledge on the subject (Ouko 2018). The study in Kenya was performed in two separate locations, the Arabuko-Sokoke Forest and the Kakamega Forest where two income-generating activities were implemented, beekeeping and silkworm-rearing (Ouko 2018). These activities would help conserve forests, because those involved in the activity realized their income would increase from forest conservation. However, the study found that less than $1 \%$ of the population participated in the projects, with $25 \%$ and $50 \%$ for lack of information, $38 \%$ and $82 \%$ choosing not to participate for lack of familiarity with the activity for the Arabuko-Sokoke and Kakamega Forests projects, respectively (Ouko 2018). 
A smooth transition to an alternate source of income occurred in the Butterfly Farm Project in Tanzania which focused on conserving forests in the East Usambara Mountains by encouraging butterfly farming (Morgan-Brown et al. 2010). The community managed the new income directly, and this resulted in individuals being more engaged from the beginning (Catacutan et al. 2007). Indeed, the alternate source of income created must be feasible and sustainable for the community members to maintain (Ochola 2013). As noted previously, community needs satisfaction and poverty alleviation ensure that the local stakeholders remain motivated and interested in continuing the project (Kepe et al. 2004).

A strong management system centred around community members with multiple stakeholders is another requirement besides skill training and alternate income sources (Page 1970). With concentration of executive power or relying to external resources the project has a higher probability of failure due to exploitation (Ochola 2013). The community must learn to manage itself and make informed decisions towards future benefit. A marine protection ICDP in Indonesia depicted the challenges of maintaining projects for a long period of time, after removing the external manager, in this case implementing marine protection in a community dependent on fisheries (Gurney et al. 2014). After the first two years of implementation, project management was passed from external project managers onto local community representatives, and subsequent productivity significantly decreased (Gurney et al. 2014). Although changes occurred during the implementation period, the local community was not sufficiently involved in the initial project stages to be able to continue effective management. The local community must be provided with tools and be properly equipped to carry on the project independently from the initial stages of planning and implementation.

A project in Sub-Saharan Africa in 1995 focused on sustainable agriculture to provide the community with an alternate source of income to unsustainable practices such as poaching (Barrett et al. 1995). The greatest challenge faced was the expectation of the project manager's to "decrease harvests following 'good years' and decrease harvests following 'bad years' " (Barrett et al. 1995). If this cycle was not properly maintained, the 'sustainable agriculture' quickly turned into an over-exploitation of resources. When weather extremes were encountered, such as droughts, there was little profit to be made from agriculture, as anything harvested was used to feed the community. Therefore, alternate sources of income were used such as poaching. Therefore, the alternate income must be profitable enough to sustain community members in the long term, and it must be properly executed and managed by individuals trusted by the community (Weber et al. 2011). Factors, such as alternate income, can be modelled over a period under stochastic conditions in a systems optimization framework to predict how this would affect the project's impact on the community.

\subsubsection{Quantitative planning and evaluation}

In the INRCD studies, several methods were used to obtain and process project data, but it is still difficult to measure the success of these projects in the long term and to compare successes across several reported INRCD studies and executions. Even the various terms used across the literature, see Figure 3, use a diversity of terminology and metrics, occasionally inconsistent, thus demonstrating the need for a more definitive, yet adaptable, process for defining INRCDs and for measuring their success quantitatively and qualitatively. Besides the terms in the figure, several other project-specific terms have been used such as Ecosystem-based Fishery Management and Participatory Forest Management. Common methods of observing changes included surveys and Likert scales. These methods are valid and useful for each situation, but they do not lead to generalizations across projects or to direct support for planning and long-term decision making. Methods that use data in a quantified manner can contribute significantly to cross-project comparisons and INRCD planning for long-term success.

Viewing an INRCD project as a system, one can argue that a system optimization modeling framework can provide decision support used by various stakeholders (Ruszczynski et al. 2013). There are extensive modeling and optimization studies on agricultural systems, fisheries, irrigation, and energy systems (Raja et al. 1998). Most of them are separate studies not related to INRCDs and those involving an INRCD project were generally used that philosophy just in the planning stages and rarely followed up later on (Manos et al. 2013). For example, a major problem is that projects often do not account for population growth. Yet population growth is exponential in many regions targeted for such projects, and communities must constantly adjust resource allocation to satisfy changing needs and to maintain profit. This was the case for the Mukogodo Forest project in the Laikipia District of Kenya where a growing population made it difficult to sustain the project in the long term (Kosgey 2015). 


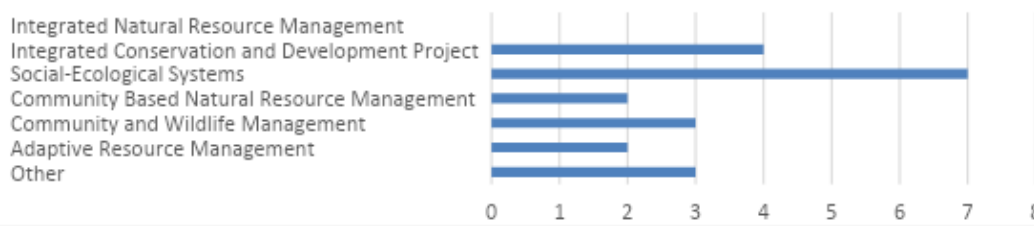

Figure 3. Frequency of various terms used in the literature

System optimization models are also more useful when accounting for resilience within a community. A system optimization model for the Amudarya River basin was split into three categories, social, irrigation, and aquatic systems (Schlüter et al. 2007) incorporating uncertainty in the social system model to account for individual needs, cost of labour, resources used for direct personal needs rather than profit, and other social aspects. Regional climate must be included in the system model to consider the impact on the number of crops harvested due to bad weather or natural disasters. In another system optimization study for a Caribbean reef project, the model aimed to maximize ecological and economic gains while also considering social aspects (Kellner et al. 2011). Another study conducted in southern Ethiopia in 2000-2003 used optimization modeling to identify alternative crop-stock production options to achieve household food and nutrition security; however, it did not consider varying social preferences and was unable to achieve food security or sufficient income for households (Amede et al. 2008). As noted earlier, quantifying social benefits is essential in maintaining the engagement of the community. Methods for measuring social value include stated preferences, life satisfaction assessments, and social impact assessments (Mulgan 2010). However, these quantitative approaches are rarely considered in projects lacking an overall cohesive success measurement.

Several optimization models focused on specific subsystems of an entire INRCD project, for example, optimization of wind-energy, agricultural production, and dairy herd management (Lu 2012; Kalantari 2015; and Manos et al. 2013, respectively). There is a limited number of studies aimed to optimize the development of an entire community. A common pattern in other whole-community studies is making the connection between optimal use of energy sources and sustainable agricultural practices. A study for the Chellampatti block of Madurai District, Tamil Nadu, India, aimed to optimize sustainable power use for land irrigation, ploughing of land, and transportation of goods (Raja et al. 1997). There is paucity of studies in the more recent years on such models. Moreover, past studies addressed conservation through sustainable agricultural practices in small scale projects and focused largely on research rather than on practice.

\section{DISCUSSION}

Although there have been optimization models that focus on smaller subsystems of a community, there are rarely larger optimization models developed that take a high-level approach. An overall system optimization model can capture the interactions among subsystems and the trade-offs among competing objectives. An example schematic of an agriculture-based INRCD project that include irrigation and an electricity microgrid for crop cultivation and household needs is depicted in Figure 4 and is currently under development (Sicko et al. 2021).

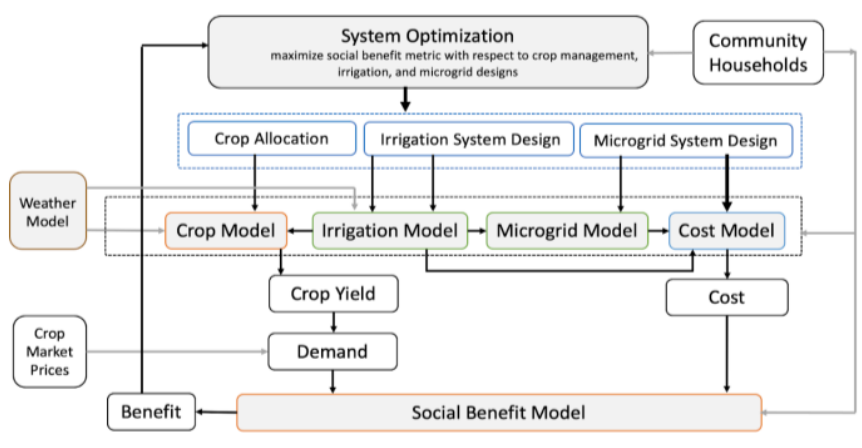

Figure 4. A system design optimization framework for an agriculture based INRCD project

A relatively simple such model may initially have maximizing profit as the optimization objective subject to operational, design, sustainability and conservation constraints. Recognizing the likely 
trade-offs between conservation and income development, a more sophisticated model would need an objective function expressing an overall social value that includes conservation and sustainability as well as development goals (Kellner et al. 2011), and include some a standard metric that measures social impact (Stevenson et al. 2018).

The framework must be constructed in a modular fashion allowing for tailoring to different projects in different regions or countries. Furthermore, the framework and its modelling elements must account for stochastic behaviour on the INRCD system, for example to account for weather and economic market patterns in the system simulation for project performance predictions. Accounting for energy and water supply, market demand, crop selection and yields, household needs, and other subsystems makes such a framework a challenging system-of-systems problem.

The value of an optimization framework as envisioned above would be amplified if used for long term, continuous planning. Moreover, a system optimization model over a time horizon can account for expanding population growth and help to adjust decisions over time so project managers can anticipate actions to prevent the return to unsustainable development practices.

\section{CONCLUDING REMARKS}

The literature review per se has limitations due to multiplicity of names used for INRCD projects, and so the review presented here is not exhaustive and it is biased towards discovery of analytical tools used. Also, more general research in design for sustainability has been excluded. Planning and implementation for some projects can take five years with another five years to begin seeing results; therefore data for current projects have not been published yet. The literature database list in the Design Society's AFRICA-DESIGN site is openly accessed and will be updated (Design Society 2021).

Certain requirements for an analysis tool of practical value emerged from the review of the studies and practices that contribute to INRCD project success: (1) Develop a generic system analysis capability with quantitative methods that support decision making, particularly over time allowing for the measurement of success across various projects; (2) Include the local community, its skills and knowledge, and account for the social benefits of the project on the community.(3) Employ a training period for community project managers with proper quantitative tools that can be used for project planning and execution.

A system design optimization framework that accounts for these requirements should include the following: (1) Model the various subsystems of the project and their interactions, employing an appropriate coordination strategy for the decisions made at the subsystem level; account for stochasticity over relatively long multi-year time periods. (2) Define one or more objective functions for the overall system which will quantify the social benefits to the community and allow for tradeoffs for other objectives, such as performance and conservation. (3) Allow for technical training in the use of such a modelling framework within at least some members of the community.

As an example, Figure 4 shows how such a framework may be constructed for an agriculture-based project relying on local sustainable energy microgrid. A systems design optimization tool can support planning and operation of INRCD projects rationally but only in the context of helping to increase project ownership, community manager training, and collection of reliable data. A modular baseline modelling environment will support a variety of project designs and executions. Beyond the modelling challenges of the first two requirements, the third requirement on training will require engagement of the local academic institutions. The next steps include constructing the modelling framework and applying it to specific case studies; connecting with the relevant local academic and community expertise; collecting data; and testing the asserted value of modelling and optimization tools.

\section{ACKNOWLEDGMENTS}

This work is part of the Design Society's AFRICA-DESIGN initiative. The Society's support is gratefully acknowledged.

\section{REFERENCES}

Ajayi, S.S. (2019). Wildlife Conservation in Africa: A Scientific Approach, Academic Press. https://doi.org/10.1016/C2018-0-01944-1 
Alpert, P. (1996). "Integrated Conservation and Development Projects.” BioScience, 46(11), 845-855. https://doi.org/10.2307/1312970

Amede, T., Delve R.J. (2008). "Modeling Crop-Livestock Systems for Achieving Food Security and Increasing Production Efficiencies in the Ethiopian Highlands." Experimental Agriculture, 44(4), 441-452. https://doi.org/10.1017/s0014479708006741

Balint, P.J. and Mashinya, J. (2006). "The decline of a model community-based conservation project: Governance, capacity, and devolution in Mahenye, Zimbabwe.” Geoforum, Vol. 37 No. 5, pp. 805-815. https://doi.org/10.1016/j.geoforum.2005.01.011

Barlow, T.W., Greene, M.T., and Papalambros, P.Y. (2020). "Review of Design Research for Sustainable Development in Africa: A Design Science Perspective." Proceedings of the Design Society: DESIGN Conference, 1, 1863-1872. https://doi.org10.1017/dsd.2020.154.

Barlow, T., Biddanda, M., Chien, C-C, Mendke, S., Miyingo, E., O’Neal, W., Sicko, A., and Papalambros, P.Y. (2021). "A System Design Optimization Model for Integrated Natural Resource Conservation and Development in an Agricultural Community." Proceedings of the Design Society: ICED Conference (this volume).

Barrett, C.B., and Arcese, P. (1995). “Are Integrated Conservation-Development Projects (ICDPs) Sustainable? On the Conservation of Large Mammals in Sub-Saharan Africa?” World Development, Vol. 23, No. 7 , 1073-1084. https://doi.org/10.1016/0305-750X(95)00031-7.

Braun, V. and Clarke, V. (2012). “Thematic Analysis.” In H. Cooper, P. M. Camic, D. L. Long, A. T. Panter, D. Rindskopf, \& K. J. Sher (Eds.), APA handbook of research methods in psychology, Vol. 2 pp. (57-71) https://doi.org/10.1037/13620-004.

Catacutan, D.C., and Tanui, J. (2007). "Engaging Stakeholders in Integrated Natural Resource Management: Approaches and Guidelines from Landcare.” Soil, Society \& Global Change, Selfoss, pp. (154-159).

Design Society (2021). Design Society Africa-Design Network. Available at africadesign.designsociety.org. Accessed 8 Dec. 2020.

Gadgil, M., Berkes, F., and Folke, C. (1993). "Indigenous Knowledge for Biodiversity Conservation.” Ambio, Vol. 22, pp. 151-156.

Gurney, G.G., Cinner, J., Ban, N.C., Pressey, R.L., Pollnac, R., Campbell, S.J., Tasidjawa, S. (2014). “Poverty and protected areas: An evaluation of a marine integrated conservation and development project in Indonesia." Global Environmental Change, Elsevier, Vol. 26 No. 1, pp. 98 - 107. https://doi.org/10.1016/j.gloenvcha.2014.04.003

INRCD Database (2021). Collection of papers examined in this review can be found in https://drive.google.com/file/d/1Am9JmxbA0gDJANpzx3NqZp9YPut639XG/view?usp=sharing.

Kalantari, A.S. (2015). Using Mathematical Modeling Techniques for Optimized Dairy Herd Management and Decision Making, Doctoral Dissertation in Dairy Science, Univ. of Wisconsin, Madison.

Kellner, J.B., Sanchirico, J.N., Hastings, A. and Mumby, P.J. (2011). “Optimizing for multiple species and multiple values: tradeoffs inherent in ecosystem-based fisheries management." Conservation Letters, Wiley-Blackwell, Vol. 4 No. 1, pp. 21-30. https://doi.org/10.1111/j.1755-263X.2010.00132.x

Kepe, T., Saruchera, M. and Whande, W. (2004). "Poverty Alleviation and Biodiversity Conservation: a South African Perspective.” Oryx, Vol. 38 No. 2, pp. 143-145. https://doi.org/10.1017/S0030605304000262

Kevork, E.K. and Vrechopoulos, A.P. (2009), "CRM Literature: Conceptual and Functional Insights by Keyword Analysis.” Emerald Insight, Vol. 27 No. 1. https://doi.org/10.1108/02634500910928362

Kosgey, B.A. (2015). An Assessment of the Implementation of Participatory Forest Management (PFM) By Ngong Road community Forest Association (CFA) in Nairobi County, Kenya. Master's Thesis in Environmental Studies, Kenyatta University, Nairobi, Kenya.

Larson, L.R. and Poudyal, N.C. (2012). "Developing sustainable tourism through adaptive resource management: a case study of Machu Picchu, Peru." Journal of Sustainable Tourism , Vol. 20 No. 7, pp. 917-938. https://doi.org/10.1080/09669582.2012.667217

Lu, S. (2011). Decomposition-based, complementarity models for renewable energy generation system design optimization. Doctoral Dissertation, Industrial and Enterprise Systems Engineering, Univ. of Illinois, Urbana-Champaign.

Makate, C., Wang, R., Makate, M. and Mango, N. (2016). "Crop Diversification and Livelihoods of Smallholder Farmers in Zimbabwe: Adaptive Management for Environmental Change.” SpringerPlus, Vol. 5, No.1135. https://doi.org/10.1186/s40064-016-2802-4

Manjengwa, J.M. (2007). "Problems Reconciling Sustainable Development Rhetoric with Reality in Zimbabwe.”Journal of Southern African Studies, Vol. 33 No. 2, pp. 307-323. https://doi.org/10.1080/03057070701292608

Manos, B., Chatzinikolaou, P. and Kiomourtzi, F. (2013). "Sustainable Optimization of Agricultural Production.”APCBEE Procedia, Vol. 5, pp. 410-415. https://doi.org/10.1016/j.apcbee.2013.05.071

Mitropoulos, S-A, Sicko, A., Frilingos, S., Aroh, N., and P.Y. Papalambros (2020). "Funding Design and Innovation for Sustainable Development in Africa: A Review of Sources." Proceedings of the Design Society: DESIGN Conference, 1, 2079-2088. https://doi.org/10.1017/dsd.2020.73. 
Morgan-Brown, T., Jacobson, S.K., Wald, K. and Child, B. (2010). "Quantitative Assessment of a Tanzanian Integrated Conservation and Development Project Involving Butterfly Farming." Conservation Biology, 24(2), 563-572. https://doi.org/10.1111/j.1523-1739.2009.01433.x

Mulgan, G (2010). Measuring Social Value. Stanford Social Innovation Review: Informing and Inspiring Leaders of Social Change.

Nhamo, G. (2019). "Higher Education and the Energy Sustainable Development Goal: Policies and Projects from University of South Africa." Sustainable Development Goals and Institutions of Higher Education, Springer, Cham, pp. 31-48. https://doi.org/10.1007/978-3-030-26157-3_3

Ochola, W.O., Sanginga, P.C. and Bekalo, I. (2013). Managing Natural Resources for Development in Africa: A Resource Book. Univ. of Nairobi Press, Nairobi, Kenya.

Ouko, E.M. (2018). "Contextualising integrated conservation and development projects: Restoring the lost 'harambee' link in Kenya.” Geoforum, Elsevier, Vol. 92, pp. 81-91.

Raja, R., Sooriamoorthi, C.E., Kanniappan, P. and Ramachandran, T. (1998). "Energy Planning and Optimization Model for Rural Development - A Case of Sustainable Agriculture.” International Journal of Energy Research, Vol. 21 No. 6, pp. 527-547. https://doig.org/10.1177/0270467614531555

Ruszczynski, A. and Shapiro, A. (2003). "Stochastic Programming Models." Handbooks in Operations Research and Management Science, Vol. 10, pp. 1-64. https://doi.org/10.1016/S0927-0507(03)10001-1

Schluter, M. and Pahl-Wostl, C. (2007). "Mechanisms of Resilience in Common-pool Resource Management Systems: An Agent-based Model of Water Use in a River Basin.” Ecology and Society, Vol. 12 No. 2. https://doi.org/10.5751.ES-02069-120404

Stevenson, P. D., Mattson, C. A., Bryden, K. M., \& MacCarty, N. A. (2018). “Toward a Universal Social Impact Metric for Engineered Products That Alleviate Poverty.” Journal of Mechanical Design, 140(4). https://doi.org/10.1115/1.4038925

Songorwa, A.N. (1999). "Community-Based Wildlife Management (CWM) in Tanzania: Are the Communities Interested?" World Development, Vol. 27, No. 12, 1999, pp. 2061-2079. https://doi.org/10.1016/S0305750X(99)00103-5

Spey, I.-K., Kupsch, D., Bobo, K.S., Waltert, M. and Schwarze, S. (2019). "The Effects of Road Access on Income Generation. Evidence from An Integrated Conservation and Development Project in Cameroon." Sustainability, Vol. 11 No. 12, 3368. https://doi.org/10.3390/su11123368

Weber, J.G., Sills, E.O., Bauch, S. and Pattanayak, S.K. (2011). "Do ICDPs Work? An Empirical Evaluation of Forest-Based Microenterprises in the Brazilian Amazon." Land Economics, Vol. 87 No. 4. https://doi.org/10.3368/le.87.4.661 